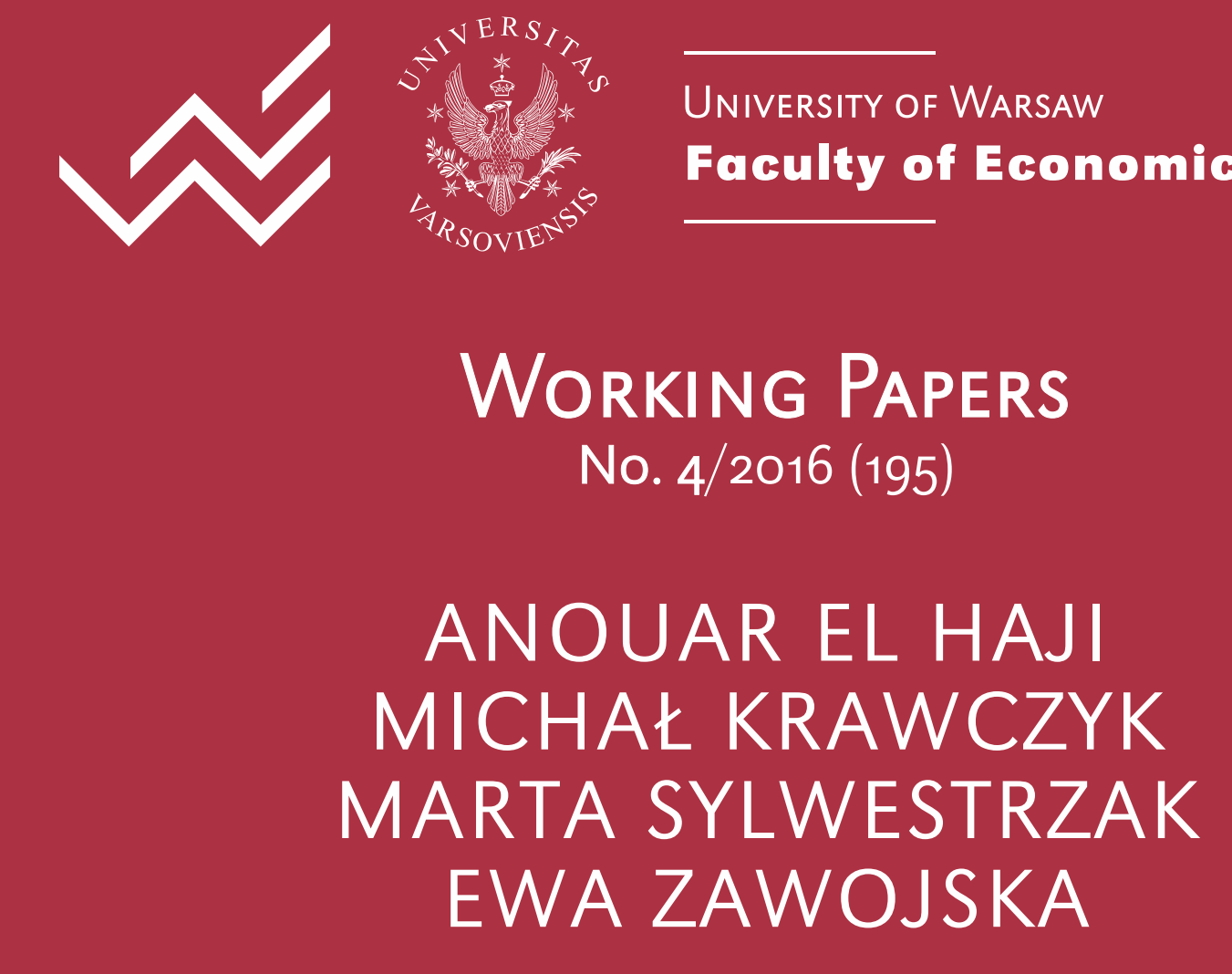

\title{
TIME PRESSURE AND RISK TAKING IN AUCTIONS: A FIELD EXPERIMENT
}




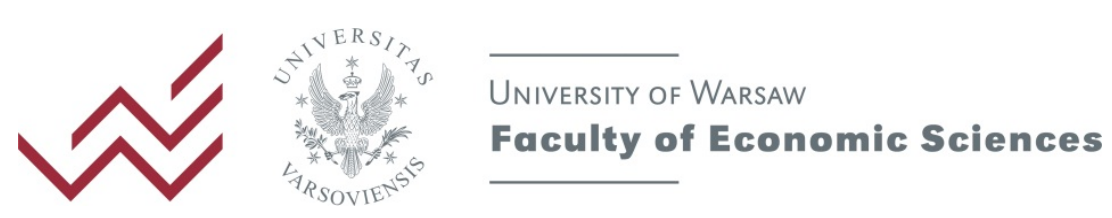

\title{
Time Pressure and Risk Taking in Auctions: A Field Experiment
}

\author{
ANOUAR EL HAJI \\ Amsterdam Business School \\ University of Amsterdam \\ e-mail: a.elhaji@uva.nl
}

MARTA SYLWESTRZAK

Faculty of Economic Sciences

University of Warsaw

e-mail: martasylwestrzak@wne.uw.edu.pl

\author{
MICHAŁ KRAWCZYK* \\ Faculty of Economic Sciences \\ University of Warsaw \\ e-mail:mkrawczyk@wne.uw.edu.pl
}

\begin{abstract}
Auctions often require risk taking under time pressure. However, little is known about how time pressure moderates the relationship between uncertainty of outcomes and bidding behavior. This study consists of a field experiment in which participants are invited to a Vickrey auction to elicit their willingness to pay for a lottery ticket. The time available to place a bid and also the skewness of the lottery (holding the expected value constant) are systematically manipulated. We find that under high time pressure participants are less likely to place a bid at all. Furthermore, participants who do place a bid under high time pressure bid significantly less than participants under low time pressure. The main finding is thus that increased time pressure significantly decreases risk taking. The effect seems to be particularly strong for the lottery with a high probability of winning and for female subjects.
\end{abstract}

\section{Keywords:}

Internet auctions, Vickrey auction, risk taking, time pressure

\author{
JEL: \\ C9, D44
}

Acknowledgments:

Authors gratefully acknowledge the support of the National Science Centre, grant UMO2014/13/B/HS4/00458. All opinions expressed are those of the authors and have not been endorsed by the NSC.

\footnotetext{
* Corresponding author: mkrawczyk@wne.uw.edu.pl 


\section{Introduction}

An overwhelming majority of human choices appear to be made very quickly. Although we may be less often forced to literally 'fight or flight' than in our ancestral past, the digital era requires snap judgments and decisions indeed. With countless stimuli appearing every minute, fast yet efficient selection and processing of information is a must. In the professional domain, for example, the ability to decide under time pressure has considerable impact on the success of air traffic controllers, emergency dispatchers, financial traders, fire fighters and surgeons (Joslyn and Hunt, 1998; Nursimulu and Bossaerts, 2014; Zakay, 1985). This emphasizes the practical importance of understanding the role of time pressure also in decision-making under risk.

One broad theoretical perspective that provides a deeper understanding of time-pressured decision-making is the dual-system approach (Stanovich and West, 2000, Kahneman, 2003). This framework proposes that there are two principal systems of thinking and deciding. System 1 is crude, intuitive, emotional, unconscious and old from evolutionary viewpoint ('the reptilian brain'). System 2 is more precise, deliberative, conscious and only evolved later ('the mammalian brain'). The crucial distinction between the two systems is that System 1 tends to be much faster because one of its evolutionary functions is to save the organism from immediate dangers. Applying severe time pressure is considered a standard experimental manipulation, because time pressure bypasses System 2 and requires System 1 to act. Indeed, time pressure is known to increase emotional arousal (Maule et al., 2000) and allow fewer cognitive deliberations, particularly when evaluating risky options (Ordóñez and Benson, 1997).

Filtration is a particularly important mechanism for System 1. Filtration occurs when it is not feasible to process all the relevant information, so that selection must take place. Thus, only the most important and salient bits of information are taken into consideration when an immediate reaction is needed (Maule et al., 2000). For example, possible losses tend to be more salient than possible gains and, therefore, filtration might lead to overemphasizing the possibility of losses or underemphasizing the possibility of gains (Loewenstein et al., 2001; Rottenstreich and Hsee, 2001). In general, there is evidence that other biases are more pronounced under time pressure (Hogarth, 1980; Kruglanski and Freund, 1983).

A pertinent economic context in which risk-taking and time pressure are ubiquitous is the use 
of auctions. Auctions facilitate exchange by eliciting binding bids from participants. To avoid paying too much or to miss out on obtaining an object at a 'fair' price, participants are incentivized to determine, based on the provided information, whether to bid and how high the bid should be. The value of the auctioned object is often uncertain and only known after the auction is won. Furthermore, auctions require that participants place their bid in a timely fashion, which is often a source of time pressure, especially if others are able to revise their bid at any moment. For example, on online auction platforms, such as eBay, participants seem to be prone to excessive revising of their bids and 'sniping' just before auction end, which forces others to respond very quickly (Ockenfels and Roth, 2002). However, little is known about how time pressure affects decision-making in an auction environment and to what extent uncertainty moderates this relationship.

This study aims to provide a deeper understanding of how time pressure affects bidding behavior. To this end a field experiment is conducted. We employ an online Vickrey auction platform to elicit bids from participants. Participants are asked to bid on a lottery ticket. The amount of time that they have to place is bid manipulated. In the Low Time Pressure Treatment (LTP) participants are allowed to spend up to six minutes to determine their bid, while in the High Time Pressure Treatment (HTP) this is only 25 seconds. To distinguish between the tendency to take more or less risk from non-linear weighting of probabilities, we compare lotteries with high and low chances of winning while holding expected value constant. The main finding is that HTP makes participants less likely to bid and less likely to bid high, especially in the case of high probability of winning.

\section{Literature review}

In line with the intuition sketched in the previous section, the main effect of time pressure in decision under risk reported in the literature is that individuals restrict their information search to certain features of the available options. Numerous studies found that decisionmakers paid less attention to positive consequences and relatively more attention to negative consequences. As a result they tend to favor relatively safe gambles (Ben Zur and Breznitz, 1981). Likewise, Kocher et al. (2013) found that, for negative prospects, participants switched from being risk-loving to being risk-averse when time limits were introduced. ${ }^{1}$ The opposite tendency was reported for positive prospects; the probability weighting function was

\footnotetext{
${ }^{1}$ Choices for gains were unaffected by time pressure and findings for mixed prospects were, nomen omen, mixed, depending on framing. Indeed, subjects seemed to pay more attention to "prominent" gains and losses when time limits were present.
} 
more elevated under a stricter time limit, which corresponds to greater risk attractiveness (Young et al., 2012). Similarly, in vignette studies, time pressure led participants to search for possible safety measures providing them with more control in the risky option ('risk defusing operators'), eventually making them choose it more often (Huber and Kunz, 2007). More recently, Madan et al. (2015) reported that time pressure induced a modest shift towards risk seeking when information about outcome probabilities was conveyed through experience rather than description.

Other studies found more nuanced effects than general attraction or aversion to risk under time pressure. Dror et al. (1999) let participants play a version of black jack, in which they repeatedly decided whether to take another card ('the risky option') or not ('the safe option'). They found that the time pressure manipulation caused a polarization effect; compared to the baseline it decreased the likelihood of taking another card when it was associated with a low probability of losing but increased this likelihood when it was associated with a high probability of losing. Such results could be interpreted in terms of reduced probability sensitivity. Likewise, Young et al. (2012) found that under time pressure probability discriminability was reduced and as a result there was more overweighting of small probabilities and more underweighting of large probabilities. A higher degree of time pressure operates in the same direction in the experiment of Nursimulu and Bossaerts (2014). Busemeyer (1985), however, found an opposite effect; there is a greater willingness to take gambles with positive expected value but lower to take gambles with negative expected value when time pressure is imposed.

The literature on time pressure in the context of auctions is mostly restricted to the phenomenon of auction fever; the tendency to deviate from previously self-imposed limits, typically resulting in overbidding. Competitive arousal results in a tendency among bidders to outcompete each other ( $\mathrm{Ku}$ et al., 2005). As an auction draws to a close, bidders who are still in the race are required to decide quickly whether to stay in the race. Indeed, studies show that time pressure increases arousal (e.g., Cates et al., 1996; Maule et al., 2000). Ku et al. (2005) observed more overbidding with respect to initially chosen limits on the last day of the auctions in their sample. ${ }^{2}$ However, it is not clear if they could successfully control for the fact that the need to ever consider such overbidding often only arises towards the end of the auction when prices are highest. In an experimental setting $\mathrm{Ku}$ et al. (2008) provided

\footnotetext{
${ }^{2}$ Their data involved results of live and Internet auctions of fiber-glass cows, pigs, moose and other animals previously featured as city symbols in various locations in the US and Canada.
} 
evidence that under the conditions of high time pressure and high stakes, arousal and the likelihood of overpaying increases.

Malhotra (2010) found that participants in a charity auction self-reported "winning, item value aside" to be more important when bidding on the last day of the auction rather than some earlier day. Malhotra (2010) also manipulated whether participants received a message about the competition between bidders or about raising money for the charity. He found that the competitive message interacted significantly with the interaction between time-pressure and rivalry to increase the probability of re-bidding. Also Adam et al.'s (2011) model emphasized that time pressure mediated by emotional arousal leads to greater deviations from initially chosen strategy, typically overbidding. In a follow-up study the effect was confirmed but only when playing against humans (Adam et al., 2015).

A particular way in which auction participants may be put under time pressure involves 'sniping' just before the auction deadline (Ockenfels and Roth, 2002). One possible explanation of the widespread use of such techniques involves assuming that bidders are uncertain about the value they attach to the object (Rasmusen, 2006; Hossain, 2008), so their opponent may want to leave them limited time to dwell on that. This would be an effective strategy if, in contrast to the concept of auction fever, time pressure encouraged more cautious bidding for objects of uncertain value. Roth and Ockenfels (2002) provided some evidence consistent with this interpretation: there is more sniping in eBay antiques auctions than in eBay computer auctions. Arguably, the former type involves more uncertainty about the value.

\section{Design and procedures}

The experiment was conducted using Veylinx, an online experimental auction platform. The platform implements the Vickrey auction to incentivize bidders to report their true valuation (Lusk and Shogren, 2007). For the focal study participants were asked to bid on a lottery. The experimental design consisted of a 2 (Probability: High, Low) x 2 (Time pressure: High, Low) between-subject design. In the Low Probability treatment (LP) the lottery paid $€ 2,000$ with a probability of 1/11 and zero otherwise (see Figure 1), and in the High Probability treatment (HP) the lottery paid $€ 200$ with the probability of $10 / 11$ and zero otherwise. The two lotteries were thus vastly different in terms of risk profile but identical in terms of expected value. Because the auctions were conducted in the form of a field experiment in the Netherlands, it was necessary to comply with Dutch commercial law. Specifically, to conform with national 
gambling regulations, the lottery was offered as a complimentary addition to a certain $€ 5$ gift card. Most notably, we also manipulated the amount of time available to participants to place a bid. In the High Time Pressure (HTP) treatment, participants had 25 seconds to place their bid. In the Low Time Pressure (LTP) participants were given 6 minutes to place bid. ${ }^{3} \mathrm{~A}$ countdown timer below the image with the lottery but above the bid entry field was shown to inform participants about the remaining time.

Figure 1. The example of the good offered in the auction (LP)

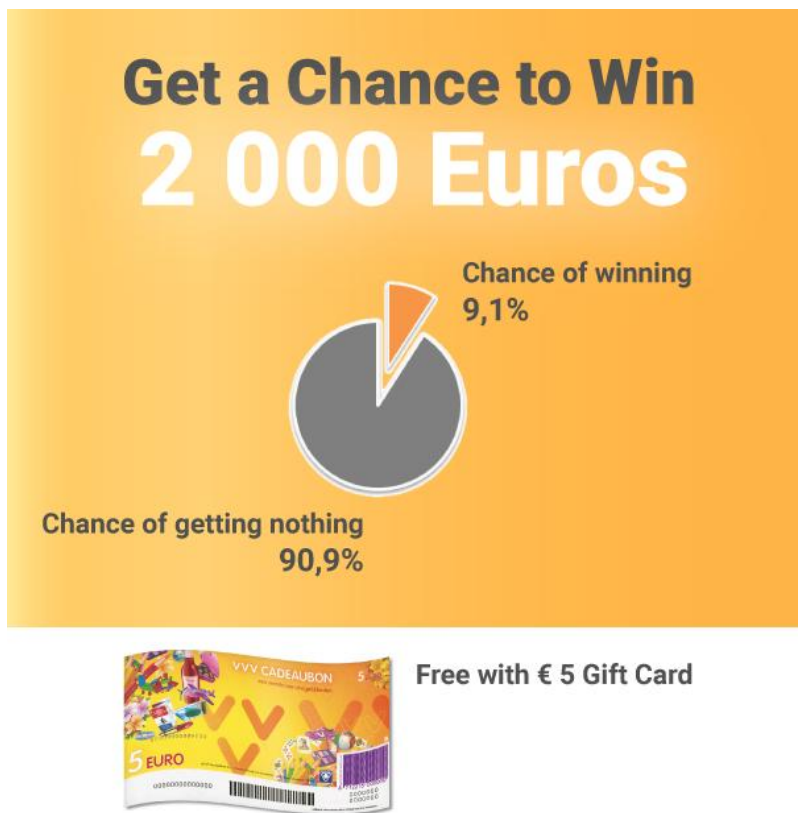

Participants were invited in the morning by e-mail to participate in the experimental auctions and the auctions were closed the same day in the evening. Participants are made aware that it is in their best interest to report their true valuation. Most participants are active users of Veylinx and, thus, experienced first-hand that truthful bidding is indeed the optimal response. The invited participants $(N=15,097)$ were randomly allocated to one of the four treatments. Participants were not informed about the existence of other treatments. The differences between treatments were only reflected in the screen in which the lottery was presented. The auction object was only shown after accepting the invitation and agreeing to the rules of the auction, upon which the clock would start. The participants were required to confirm their bid to make sure that they consent with the amount. Those who did not place their bid within the

\footnotetext{
${ }^{3}$ It had been established in a pilot study that for majority of participants 25 seconds was enough to make a meaningful, yet time-pressured decision. By contrast, six minutes was more than anybody needed.
} 
time limit were forced to the next screen that informed participants that they had failed to place a bid within the time limit. After placing a bid participants were asked to fill out a short survey to measure their understanding of the shown lottery, perceived time pressure and decision style (deliberative versus intuitive). Furthermore, participants were asked whether they consciously considered the expected value of the lottery to determine their bid. (See Appendix A for an English translation of the survey.) The winners of the auctions were contacted by e-mail and were required to pay the second-highest bid within 48 hours, which they all did. After payment, the winners were contact to set a time and date to resolve the lottery. The lottery was resolved using a reputable online random number generator.

In total, 1,679 individuals accepted the invitation to participate in the experimental auctions run in May and June 2015, of which 986 submitted their bids within the time limit. The distribution of participants across the four treatments is shown in Table 1. The share of participants who did not submit any bid within time limit was generally quite high, especially under HTP (while no differences between LP and HP were observed).

Table 1. The share of subjects and bids submitted within time limit in each treatment

\begin{tabular}{l|c|c}
\hline & Low Probability & High Probability \\
\hline Low Time Pressure & $25.8 \% ; 70.2 \%$ & $23.1 \% ; 74.2 \%$ \\
\hline High Time Pressure & $28.0 \% ; 46.4 \%$ & $23.1 \% ; 45.5 \%$ \\
\hline
\end{tabular}

Notes. $N=1,679$. The first number in each cell represents the share of participants of a given treatment in the complete sample. The second number indicates the fraction of participants (out of all participants in a given treatment) who placed a bid within the time limit.

\section{Results}

\subsection{Manipulation check}

Participants' decision to place a bid were indeed much faster under HTP than under LTP. Moreover, they perceived stronger time pressure (Table 2). 
Table 2. Subjects made faster, more time-pressured, and more intuitive decisions under HTP

\begin{tabular}{|c|c|c|c|c|}
\hline & & LTP & HTP & LTP vs. HTP \\
\hline \multirow{3}{*}{ LP } & Median time & 28 & 18 & $p<0.001(\mathrm{M}-\mathrm{W})$ \\
\hline & Perceived time press. & 1.64 & 2.77 & $p<0.001(\mathrm{M}-\mathrm{W})$ \\
\hline & Fraction intuitive & $40.00 \%$ & $61.45 \%$ & $p<0.001($ Pr-test $)$ \\
\hline \multirow{3}{*}{ HP } & Median time & 32 & 19 & $p<0.001(\mathrm{M}-\mathrm{W})$ \\
\hline & Perceived time press. & 1.73 & 2.90 & $p<0.001(\mathrm{M}-\mathrm{W})$ \\
\hline & Fraction intuitive & $47.20 \%$ & $66.41 \%$ & $p<0.001$ (Pr-test) \\
\hline LP & Median time & $p=0.01(\mathrm{M}-\mathrm{W})$ & $p=0.51(\mathrm{M}-\mathrm{W})$ & \\
\hline vs. & Perceived time press. & $p=0.14(\mathrm{M}-\mathrm{W})$ & $p=0.39(\mathrm{M}-\mathrm{W})$ & \\
\hline HP & Fraction intuitive & $p=0.06$ (Pr-test) & $p=0.19$ (Pr-test) & \\
\hline
\end{tabular}

Notes. The three numbers in each cell of the two central columns represent median bidding time, self-reported perceived time pressure from 1 ('no time pressure') to 5 ('very strong pressure') and the fraction of participants who reported to decide about their bid intuitively rather than deliberately ('no opinion' category is ignored), respectively. Only participants that placed a bid within the time limit are included in this analysis. M-W stands for Mann-Whitney test and Pr-test for the test of proportions.

Subjects were also asked to indicate if they considered expected value of the lottery when making their decisions about the bid amount. Table 3 shows the distribution of participants' self-reports concerning considering the expected value in each treatment. The distributions under LTP and HTP were weakly significantly different both in LP and HP treatments, with the main effect of time pressure being that less individuals declared having considered EV and other factors, as we could expect based on extant literature.

Table 3. Subjects were slightly more likely to disregard expected value under HTP

\begin{tabular}{|l|c|c|c|c|}
\cline { 2 - 5 } \multicolumn{1}{c|}{} & \multicolumn{2}{c|}{ Low Probability } & \multicolumn{2}{c|}{ High Probability } \\
\cline { 2 - 5 } \multicolumn{1}{c|}{} & LTP & HTP & LTP & HTP \\
\hline Considered only EV & $12.96 \%$ & $13.50 \%$ & $13.94 \%$ & $11.46 \%$ \\
\hline Considered EV and other factors & $25.56 \%$ & $15.68 \%$ & $20.72 \%$ & $12.74 \%$ \\
\hline Did not consider EV & $44.44 \%$ & $55.14 \%$ & $45.42 \%$ & $49.05 \%$ \\
\hline No opinion & $17.04 \%$ & $15.68 \%$ & $19.92 \%$ & $26.75 \%$ \\
\hline Chi-squared test: LTP vs. HTP & \multicolumn{3}{c|}{$p=0.053$} & \multicolumn{2}{c|}{$p=0.102$} \\
\hline Chi-squared test: LP vs. HP & \multicolumn{3}{c|}{ under LTP: 0.569 under HTP: 0.093} \\
\hline
\end{tabular}

\subsection{Treatment effects}

We now turn to comparison of the submitted bids. Figures 2 and 3 show cumulative distribution functions (CDFs) for each of the four treatments. Bids were lower under high time pressure and the difference was much more pronounced under HP than under LP. Likewise, HP and LP were substantially different under LTP only. These observations are confirmed by formal statistical tests (Table 4). 
Figure 2. CDFs of bid amount under LP condition

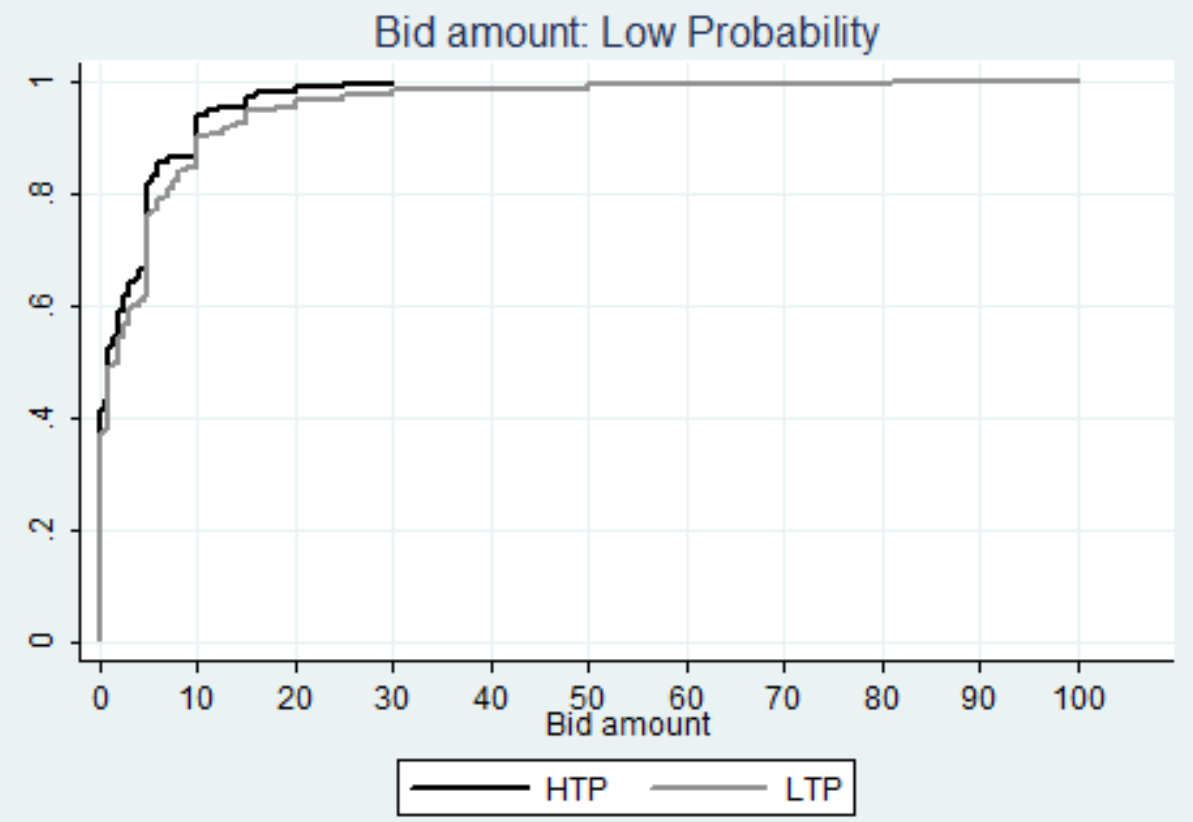

Figure 3. CDFs of bid amount under HP condition

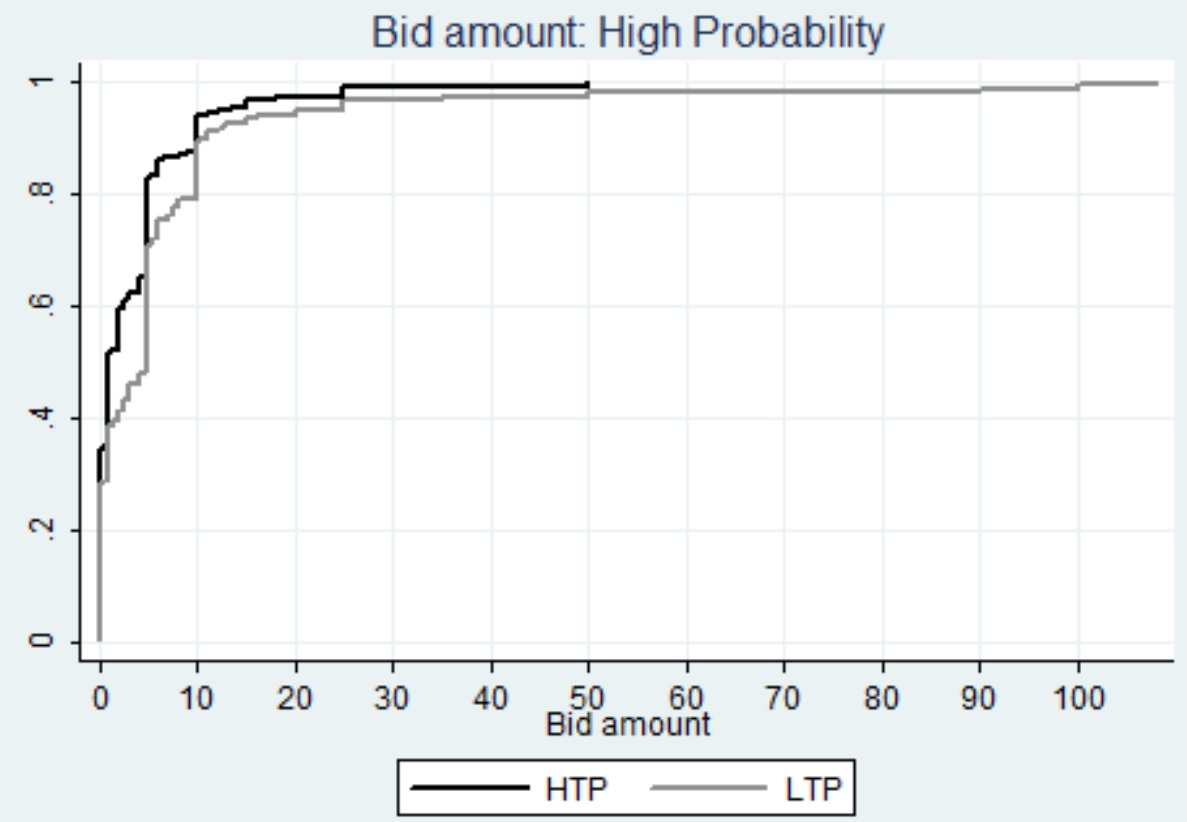


Table 4. Bids were lower under time pressure in HP condition

\begin{tabular}{|c|c|c|c|c|}
\hline & & LTP & HTP & LTP vs. HTP \\
\hline \multirow{5}{*}{ LP } & Mean bid amount & 4.88 & 3.28 & \multirow{5}{*}{$\mathrm{z}=1.367, p=0.17(\mathrm{M}-\mathrm{W})$} \\
\hline & Standard deviation & 9.95 & 4.75 & \\
\hline & Median & 2 & 1 & \\
\hline & Percentage of bids equal to 0 & $35.86 \%$ & $39.91 \%$ & \\
\hline & Mean non-zero bid amount & 7.61 & 5.46 & \\
\hline \multirow{5}{*}{ HP } & Mean bid amount & 6.95 & 3.82 & \multirow{5}{*}{$\mathrm{z}=3.096, p=0.002(\mathrm{M}-\mathrm{W})$} \\
\hline & Standard deviation & 15.14 & 6.76 & \\
\hline & Median & 5 & 1 & \\
\hline & Percentage of bids equal to 0 & $27.18 \%$ & $33.33 \%$ & \\
\hline & Mean non-zero bid amount & 9.55 & 5.73 & \\
\hline $\begin{array}{l}\text { LP } \\
\text { vs. } \\
\text { HP }\end{array}$ & Mean bid amount & $\begin{array}{c}z=-2.74 \\
p=0.006 \\
(M-W)\end{array}$ & $\begin{array}{c}z=-0.73 \\
p=0.46 \\
(\mathrm{M}-\mathrm{W})\end{array}$ & \\
\hline
\end{tabular}

Table 5 shows correlations between bid amounts and response time for bidders who decided to participate in the auction and submit a non-zero bid.

Table 5. Correlations between bid amount and response time

\begin{tabular}{|c|c|c|}
\cline { 2 - 3 } \multicolumn{1}{c|}{} & LTP & HTP \\
\hline \multirow{2}{*}{ LP } & 0.42 & 0.13 \\
& $p<0.001$ & $p=0.13$ \\
\hline \multirow{2}{*}{ HP } & 0.33 & 0.09 \\
& $p<0.001$ & $p=0.34$ \\
\hline
\end{tabular}

We do not observe significant correlations between bid amount and response time in the HTP treatment. By contrast, in the LTP treatment participants tend to bid higher after longer deliberation, a tendency that echoes the treatment effect.

To see if treatment effects operate uniformly across genders we have looked at distributions of bids made by males and females only. Generally, female bidders tend to bid lower, see Table 6. 
Table 6. Females' bids were lower

\begin{tabular}{|c|c|l|c|c|c|}
\cline { 3 - 5 } \multicolumn{2}{c|}{} & Male & Female & M-W \\
\hline \multirow{4}{*}{ LP } & \multirow{2}{*}{ LTP } & Mean bid amount & 6.56 & 2.97 & $z=1.61 ; p=0.108$ \\
& & Standard deviation & 12.97 & 3.70 & \\
\cline { 3 - 6 } & \multirow{2}{*}{ HTP } & Mean bid amount & 3.92 & 2.60 & $z=1.27 ; p=0.203$ \\
& & Standard deviation & 5.49 & 3.72 & \\
\hline \multirow{4}{*}{ HP } & \multirow{2}{*}{ LTP } & Mean bid amount & 10.24 & 4.27 & $z=2.18 ; p=0.029$ \\
\cline { 3 - 6 } & \multirow{2}{*}{ HTP } & Standard deviation & 21.43 & 5.22 & \\
& & Mean bid amount & 5.17 & 2.45 & $z=2.12 ; p=0.034$ \\
& & Standard deviation & 8.74 & 3.38 & \\
\hline
\end{tabular}

Calculating gender-specific treatment effects we find that under the HP condition the difference in bid amount between LTP and HTP is significant for both men (M-W, $z=1.96 ; p$ $=0.05)$ and women $(\mathrm{M}-\mathrm{W}, z=2.68 ; p=0.007)$. In the LP condition we do not observe these differences neither for men $(\mathrm{M}-\mathrm{W}, z=1.01 ; p=0.31)$ nor women $(\mathrm{M}-\mathrm{W}, z=1.04 ; p=0.30)$.

Because the number of missing bids is high and treatment-specific, as shown in Table 1, this analysis may not be fully satisfactory, as we do not know what was the bidding intention of the individuals who did not submit any bid. One natural interpretation is that they were reluctant to submit any positive bid. We can thus re-run the tests for treatment effects, this time treating all the missing bids as if they were zero bids. Because the fraction of missing bids is higher in the HTP, this only strengthens our results concerning the impact of time pressure: in LP treatment: $z=4.20, p<0.001(\mathrm{M}-\mathrm{W})$; in HP treatment: $z=4.79, p<0.001$ $(\mathrm{M}-\mathrm{W})$.

The high fraction of missing bids might have also distorted treatment effects via selection. For example, if men tend to submit higher bids than women but they are more often reluctant to submit any bid under time pressure, lower bids under time pressure would result, even if any individual's bidding behavior, conditional on submitting any bid at all, was not altered by time pressure. To address this issue, we have used regression analysis to check if treatment effects persist if other explanatory variables are controlled for.

In our modelling approach we take into account possible selection related to whether participants place any bid at all, and to whether participants submit a bid higher than zero. In order to control for these selection effects, we first model two binary variables, namely whether a participant submitted any bid, and whether a participant submitted a non-zero bid (conditional on that the participant submitted a bid), using the probit approach to each. Then, from the bivariate probit procedure, we calculate the double-selection analogs of the inverse Mill's ratios typically obtained in the single-selection context, which we subsequently 
employ in modelling of bid amount as a continuous variable in an OLS regression. ${ }^{4}$ The three equations that we estimate could be formally represented by

$$
\begin{gathered}
\text { Bid_anything }=\alpha_{1}+\beta_{1}{ }^{\prime} X+\varepsilon_{1}, \\
\text { Nonzero_bid }=\alpha_{2}+\beta_{2}{ }^{\prime} X+\varepsilon_{2}, \\
\ln (\text { bid_amount })=\alpha_{3}+\beta_{3}{ }^{\prime} X+\varepsilon_{3},
\end{gathered}
$$

where Bid_anything is a binary variable equal to 1 if a participant placed a bid within the relevant time limit; Nonzero_bid is a binary variable equal to 1 if a participant placed a non-zero bid within time limit; $\ln$ (bid_amount) is a natural logarithm of bid amount calculated for positive bid amounts; $X$ is a vector of explanatory variables; $\beta_{1}, \beta_{2}$ and $\beta_{3}$ are the corresponding vectors of coefficients to be estimated; $\alpha_{1}, \alpha_{2}$ and $\alpha_{3}$ are the constant terms; $\varepsilon_{1}, \varepsilon_{2}$ and $\varepsilon_{3}$ are the error terms. Table 7 reports the estimation results. We present

\begin{tabular}{|c|c|c|c|c|c|c|}
\hline & \multicolumn{2}{|c|}{$\begin{array}{c}\text { Equation (1) } \\
\text { Dependent variable: } \\
\text { Bid_anything }\end{array}$} & \multicolumn{2}{|c|}{$\begin{array}{c}\text { Equation (2) } \\
\text { Dependent variable: } \\
\text { Nonzero_bid }\end{array}$} & \multicolumn{2}{|c|}{$\begin{array}{c}\text { Equation (3) } \\
\text { Dependent variable: } \\
\ln (\text { bid_amount })\end{array}$} \\
\hline & A & B & A & B & A & B \\
\hline HTP & $-0.632 * * *$ & $-0.533 * * *$ & -0.002 & -0.080 & $-5.456^{* * *}$ & $-2.923^{*}$ \\
\hline$H P$ & -0.021 & $0.120 *$ & 0.416 *** & $0.307 * * *$ & $4.548 * * *$ & $2.118^{* *}$ \\
\hline female & $-0.393 * * *$ & $-0.209 * * *$ & 0.031 & -0.127 & $-3.150 * * *$ & $-1.992^{* *}$ \\
\hline age & $-0.007 * * *$ & $-0.007 * * *$ & $-0.007 * *$ & $-0.007 * *$ & $-0.149 * * *$ & $-0.072 * *$ \\
\hline$H T P \times H P$ & 0.087 & & -0.033 & & -0.210 & \\
\hline HTP $\times$ female & 0.197 & & -0.171 & & $-1.185^{* * *}$ & \\
\hline HP $\times$ female & 0.268 & & -0.221 & & -0.092 & \\
\hline$H T P \times H P \times$ female & -0.190 & & 0.092 & & 0.114 & \\
\hline Constant & $1.191 * * *$ & $1.103^{* * *}$ & $0.572 * * *$ & $0.638 * * *$ & $-12.2 * *$ & -4.394 \\
\hline$I M R_{-} 1$ & & & & & -127900 & 4873 \\
\hline$I M R \_2$ & & & & & $24.71 * * *$ & $11.32 *$ \\
\hline $\mathrm{R}^{2}$ & & & & & 0.063 & 0.055 \\
\hline Adjusted $\mathrm{R}^{2}$ & & & & & 0.050 & 0.047 \\
\hline F-statistics & & & & & $4.923 * * *$ & $7.123^{* * *}$ \\
\hline Null deviance & $2,119.4$ & $2,119.4$ & 1,458 & 1,458 & & \\
\hline $\begin{array}{l}\text { Reduced } \\
\text { deviance }\end{array}$ & $2,025.7$ & 2028.5 & 1,434 & $1,436.1$ & & \\
\hline No. of obs. & \multicolumn{2}{|c|}{1,679} & \multicolumn{2}{|c|}{1,132} & \multicolumn{2}{|c|}{742} \\
\hline
\end{tabular}
two model specifications, A and B, with and without interactions, respectively.

Table 7. Regression results: less risk taking under time pressure

Notes: A and B are alternative specifications: with and without interactions, respectively. $I M R_{-} l$ and $I M R \_2$ are selectivity corrections from the equations (1) and (2), respectively. $* p<0.05$; ** $p<0.01$; *** $p<0.001$.

\footnotetext{
${ }^{4}$ The procedure was initially proposed by Tunali (1986), who extended the standard Heckman's procedure to include a double-selection rule.
} 
The probit regression (1) confirms the previously reported result that subjects were less likely to submit any valid bid under HTP than under LTP. Interestingly, whether the lottery pays a positive amount with high or low probability (HP condition vs. LP condition) does not influence significantly the chances whether the participant will submit any bid when the interactions are included (specification A). However, when we exclude the interactions from the model (specification B), we observe that subjects were more likely to submit any bid under HP condition. Furthermore, females and older individuals are less likely to place any bid within the time limit.

The probit regression (2) informs that the probability of submitting a non-zero bid is higher for the participants assigned the HP lottery than those with the LP lottery. Further, the results reveal that time pressure does not affect the probability whether a participant submits a positive bid. Older age appears to decrease the probability of submitting a non-zero bid.

The OLS regression (3), which incorporates the selection effects obtained from the bivariate probit procedure, shows that HTP affects bid amounts negatively, while in HP condition participants bid more. Both age and being a female decrease the bid amount. The negative impact of HTP on the bid amount is even intensified for females. Interactions between HP and HTP are not significant. Statistical significance of the coefficient by the selectivity correction from equation (2) confirms that the selection exists.

\subsection{Types}

We now turn to analyzing different types of decision makers. Table 8 compares bids of subjects who said they took expected value into account when making their decision (perhaps next to other factors) to those who did not. Because bids were generally much lower than the expected value, we expect that considering it would increase the bids, as observed (for mixed prospects) by Kocher et al. (2013). This is confirmed by statistical tests, but only in the LTP condition.

Table 8. Bidders' types: considering expected value was associated with higher bids

\begin{tabular}{|c|l|c|c|c|}
\cline { 2 - 4 } \multicolumn{2}{|c|}{ LTP } & Considered EV & Did not consider EV & MW \\
& Standard deviation & 10.45 & 3.78 & $z=-3.23, p=0.001$ \\
\hline \multirow{2}{*}{ HTP } & Mean bid amount & 4.48 & 4.96 & \\
& Standard deviation & 7.79 & 3.42 & $z=-0.468, p=0.64$ \\
\hline Non-zero bids only: & 4.28 & \\
\hline \multirow{2}{*}{ LTP } & Mean bid amount & 14.36 & 5.29 & $z=-4.84, p<0.001$ \\
& Standard deviation & 22.82 & 5.14 & \\
\hline HTP & Mean bid amount & 7.25 & 4.97 & $z=-1.15, p=0.25$ \\
& Standard deviation & 8.55 & 4.36 & \\
\hline
\end{tabular}


Next, we compare subjects who reported to have made their decisions intuitively versus those who did it deliberately (Table 9).

Table 9. Bidders' types: intuitive and deliberate bidders behaved differently

\begin{tabular}{|c|l|c|c|c|}
\cline { 2 - 4 } \multicolumn{2}{l|}{} & Intuitive & Deliberate & MW \\
\hline LTP & Mean bid amount & 6.50 & 6.69 & $z=3.41, p=0.002$ \\
& Standard deviation & 11.90 & 15.74 & \\
\hline HTP & Mean bid amount & 4.29 & 2.88 & $z=3.18, p=0.001$ \\
& Standard deviation & 6.08 & 4.91 & \\
\hline Non-zero bids only: \\
\hline LTP & Mean bid amount & 7.90 & 10.36 & $z=0.22, p=0.82$ \\
& Standard deviation & 12.69 & 18.61 & \\
\hline \multirow{2}{*}{ HTP } & Mean bid amount & 5.72 & 5.50 & $z=-0.20, p=0.84$ \\
& Standard deviation & 6.42 & 5.63 & \\
\hline
\end{tabular}

While the distribution of bids is significantly different between intuitive and deliberate decision makers, the nature of this difference depended on time pressure condition. Under high time pressure deliberation was associated with (extremely) low bids. By contrast, with more time pressure, deliberation led to polarized bidding (higher standard deviation). Presumably some of the deliberate bidders drew closer to expected value, while others might have possibly come to the conclusion that there is little chance to win the auction anyway and signaled their negative attitude with a very low bid. The statistics for positive bids indicate that the effects described above were mostly due to differences in the fraction of zero bids.

\section{Discussion and conclusions}

The aim of this study is to shed light on how time pressure affects risk taking in auctions. Previous studies primarily focus on endogenous time pressure due to increased competition. To our knowledge, this is the first study that manipulates time pressure exogenously to investigate its impact on bidding behavior in auctions with uncertain outcomes.

The main finding is that high time pressure discourages taking a chance. The effect is likely to be related to the feeling of being insufficiently informed. Gretschko and Rajko (2015) argue that such a perception may lead to submitting bids that are significantly below the theoretically optimal level. A possible explanation for this pattern is an aversion to making choices that might induce regret.

The nonparametric analysis suggests that the effect is particularly strong for lotteries with high probability of the good outcome. Arguably, this is the most relevant case for typical auctions. Indeed, they represent a right-skewed gamble - there is only a small probability that the seller will deliver no product at all or a product considerably deviating from its 
description, that the product will be damaged in transportation or for some reason will turn out to be useless etc. If such low-probability risks indeed appear particularly unattractive under time pressure, several conclusions follow.

First, it provides an explanation for sniping. Leaving the opponent only limited time to decide whether or not to bid on makes it more likely that she gives up. Of course, further empirical work may be needed to verify that this proves profitable. Our experiment was designed to address the impact of time pressure on risk-taking in auctions in the simplest possible way. It remains to be seen if time pressure also diminishes willingness to rebid in a dynamic auction. If not, it may possibly explain apparent contrast between our results and those in the literature on "auction fever". It must immediately be noted, however, that those studies often allow no clear inference about the role of time. Instead, they focus on competitive pressure rather than time pressure as such.

Second, our finding contributes to the literature on optimal auction duration (Haruvy and Leszczyc, 2010). It suggests that overly short auction duration may have a detrimental effect on revenues in the case of auctions, in which non-trivial uncertainty about the product is involved.

Third, more broadly, it provides additional evidence roughly consistent with the notion of non-linear probability weighting influenced by affect (Rottenstreich and Hsee, 2001). When our subjects only have limited deliberation time, they act more intuitively and emotionally, which appears to make them attach excessively high weight to the unattractive outcome, substantially lowering bids in the case of HP. It must be noted, however, that the analogous mechanism of (positive) emotions (such as hope) increasing the weight of the unlikely good outcome under LP does not seem to be present or at least strong enough to counterbalance the overall caution induced by time pressure.

The between-subject design of our study did not allow revealing the effect of time pressure at the individual level. A possible solution to this challenge is to require participants to bid in subsequent auctions with different time limits. The order of the auctions should be randomized to control for any order effects and only a single auction is implemented to avoid any income effects. 


\section{References}

Adam, M. T., Krämer, J., Jähnig, C., Seifert, S., and Weinhardt, C. (2011). Understanding auction fever: A framework for emotional bidding. Electronic Markets, 21(3), 197-207.

Adam, M. T., Krämer, J., and Müller, M. B. (2015). Auction fever! How time pressure and social competition affect bidders' arousal and bids in retail auctions. Journal of Retailing, 91(3), 468-485

Ben Zur, H., and Breznitz, S. J. (1981). The effect of time pressure on risky choice behavior. Acta Psychologica, 47(2), 89-104.

Busemeyer, J. R. (1985). Decision making under uncertainty: A comparison of simple scalability, fixed-sample, and sequential-sampling models. Journal of Experimental Psychology: Learning, Memory, and Cognition, 11(3), 538-564

Maule, A. J., Hockey, G. R., \& Bdzola, L. (2000). EVects of time-pressure on decisionmaking under uncertainty: Changes in aVective $\mathrm{G}$. Ku et al. / Organizational Behavior and Human Decision Processes 96 (2005) 89-103 103 states and information processing strategy. Acta Psychologica, 104(3), 283-301.

Cates, D. S., Shontz, F. C., Fowler, S., Vavak, C. R., Dell'Oliver, C., \& Yoshinobu, L. (1996). The eVects of time pressure on social cognitive problem-solving by aggressive and nonaggressive boys. Child Study Journal, 26(3), 163-191.

Dror, I. E., Basola, B., and Busemeyer, J. R. (1999). Decision making under time pressure: An independent test of sequential sampling models. Memory and Cognition, 27(4), 713-725.

Gretschko, V., and Rajko, A. (2015). Excess information acquisition in auctions. Experimental Economics, 18(3), 1-21.

Haruvy, E., \& Leszczyc, P. T. P. (2010). The impact of online auction duration. Decision Analysis, 7(1), 99-106.

Hogarth, R. (1980). Judgement and choice. New York: John Wiley.

Hossain, T. (2008). Learning by bidding. The RAND Journal of Economics, 39(2), 509-529.

Huber, O., and Kunz, U. (2007). Time pressure in risky decision-making: Effect on risk defusing. Psychology Science, 49(4), 415.

Joslyn, S., \& Hunt, E. (1998). Evaluating individual differences in response to time-pressure situations. Journal of Experimental Psychology, 4(1), 16-43.

Kahneman, Daniel. (2003). "A Perspective on Judgement and Choice: Mapping Bounded Rationality," American Psychologist 58, 697-720.

Kocher, M. G., Pahlke, J., \& Trautmann, S. T. (2013). Tempus fugit: time pressure in risky decisions. Management Science, 59(10), 2380-2391.

Kruglanski, A. W., \& Freund, T. (1983). The freezing and unfreezing of lay-inferences: Effects on impressional primacy, ethnic stereotyping, and numerical anchoring. Journal of Experimental Social Psychology, 19, 448-468

Ku, G., Malhotra, D., and Murnighan, J. K. (2005). Towards a competitive arousal model of decision-making: A study of auction fever in live and Internet auctions. Organizational Behavior and Human Decision Processes, 96(2), 89-103.

Ku, G., Galinsky, A. D., and Murnighan, J. K. (2008). Arousal, interest and auction bidders. 
IACM 21 st Annual Conference Paper, November, 9.

Loewenstein, G. F., Weber, E. U., Hsee, C. K., and Welch, N. (2001). Risk as feelings. Psychological Bulletin, 127(2), 267-286.

Lusk, J. L., and Shogren, J. F. (2007). Experimental auctions: Methods and applications in economic and marketing research. Cambridge University Press.

Madan, C. R., Spetch, M. L., and Ludvig, E. A. (2015). Rapid makes risky: Time pressure increases risk seeking in decisions from experience. Journal of Cognitive Psychology, 27(8), 921-928.

Malhotra, D. (2010). The desire to win: The effects of competitive arousal on motivation and behavior. Organizational fBehavior and Human Decision Processes, 111(2), 139-146.

Maule, A. J., Hockey, G. R. J., and Bdzola, L. (2000). Effects of time-pressure on decisionmaking under uncertainty: Changes in affective state and information processing strategy. Acta Psychologica, 104(3), 283-301.

Nursimulu, A. D., and Bossaerts, P. (2014). Risk and reward preferences under time pressure. Review of Finance, 18(3), 999-1022.

Ordóñez, L., \& Benson III, L. (1997). Decisions under time pressure: How time constraint aVects risky decision making. Organizational Behavior and Human Decision Processes, 71(2), 121-140.

Roth, A. E., \& Ockenfels, A. (2002). Last minute bidding and the rules for ending second price auctions: evidence from ebay and amazon auctions on the internet. American Economic Review, 92(4), 1093-1103.

Rasmusen, E. B. (2006). Strategic implications of uncertainty over one's own private value in auctions. Advances in Theoretical Economics, 6(1), 1-22.

Roth, A. E., and Ockenfels, A. (2002). Last minute bidding and the rules for ending second price auctions: Evidence from eBay and Amazon auctions on the Internet. American Economic Review, 92(4), 1093-1103.

Rottenstreich, Y., and Hsee, C. K. (2001). Money, kisses, and electric shocks: On the affective psychology of risk. Psychological Science, 12(3), 185-190.

Stanovich, K. E., and West, R. F. (2000). "Individual Differences in Reasoning: Implications for

the Rationality Debate," Behavioral and Brain Sciences 23, 645-726.

Tunali, I. (1986). A general structure for models of double-selection and an application to a joint migration/earnings process with remigration. Research in Labor Economics, 8(Part B), 235-282.

Tversky, A., and Kahneman, D. (1992). Advances in prospect theory: Cumulative representation of uncertainty. Journal of Risk and uncertainty, 5(4), 297-323.

Young, D. L., Goodie, A. S., Hall, D. B., and Wu, E. (2012). Decision making under time pressure, modeled in a prospect theory framework. Organizational Behavior and Human Decision Processes, 118(2), 179-188.

Zakay, D. (1985). Post-decision confidence and conflict experienced in a choice process. Acta Psychologica. 58, 75-80. 


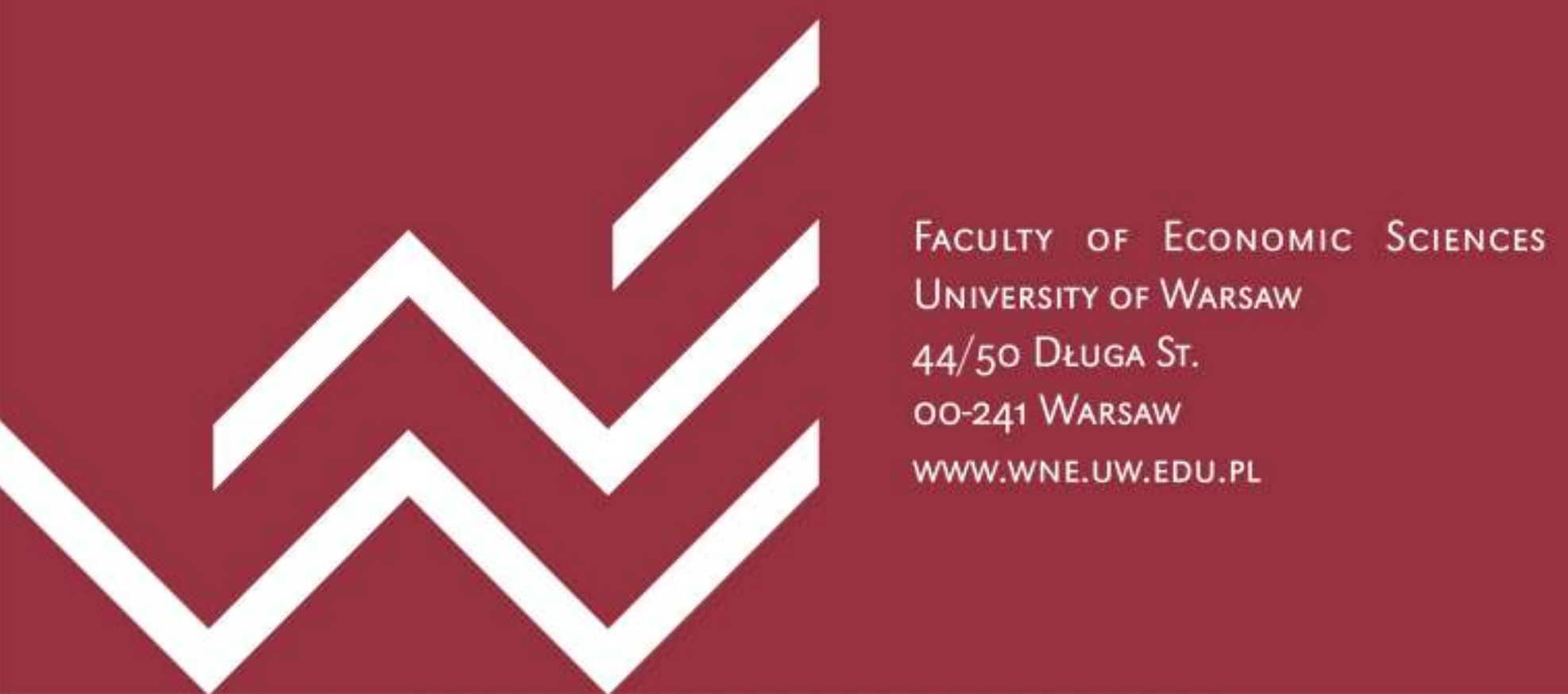

